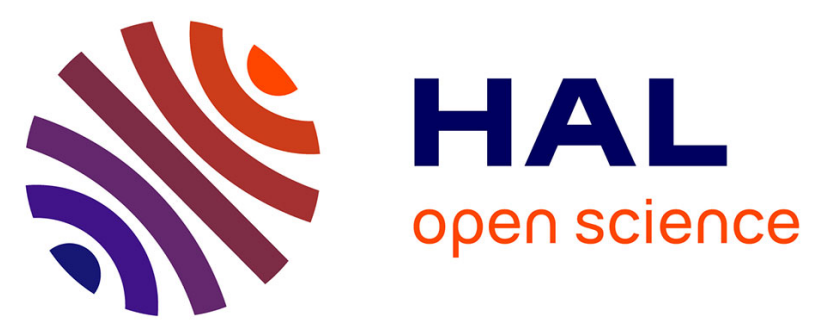

\title{
Silver(I) Oxide-/DBU-Promoted Synthesis of Dihydrofuran Units through Allenyl Silver Formation
}

Bao Yu, Anna Perfetto, Luca Allievi, Sabrina Dhambri, Marie-noelle Rager, Mohamed Selkti, Ilaria Ciofini, Marie-Isabelle Lannou, Geoffroy Sorin

\section{- To cite this version:}

Bao Yu, Anna Perfetto, Luca Allievi, Sabrina Dhambri, Marie-noelle Rager, et al.. Silver(I) Oxide/DBU-Promoted Synthesis of Dihydrofuran Units through Allenyl Silver Formation. Chemistry - A European Journal, In press, 10.1002/chem.202002696 hal-03044183

\section{HAL Id: hal-03044183 https://hal.science/hal-03044183}

Submitted on 7 Dec 2020

HAL is a multi-disciplinary open access archive for the deposit and dissemination of scientific research documents, whether they are published or not. The documents may come from teaching and research institutions in France or abroad, or from public or private research centers.
L'archive ouverte pluridisciplinaire HAL, est destinée au dépôt et à la diffusion de documents scientifiques de niveau recherche, publiés ou non, émanant des établissements d'enseignement et de recherche français ou étrangers, des laboratoires publics ou privés. 


\title{
Silver(I) oxide - /DBU - promoted synthesis of dihydrofuran units through allenyl silver formation
}

\author{
Bao Yu[a], Anna Perfetto[b], Luca Allievi[a], Sabrina Dhambri[a], Marie-Noelle Rager ${ }^{[b]}$, Mohamed Selkti[a], Ilaria \\ Ciofini[b], Marie-Isabelle Lannou*[a], and Geoffroy Sorin *[a]
}

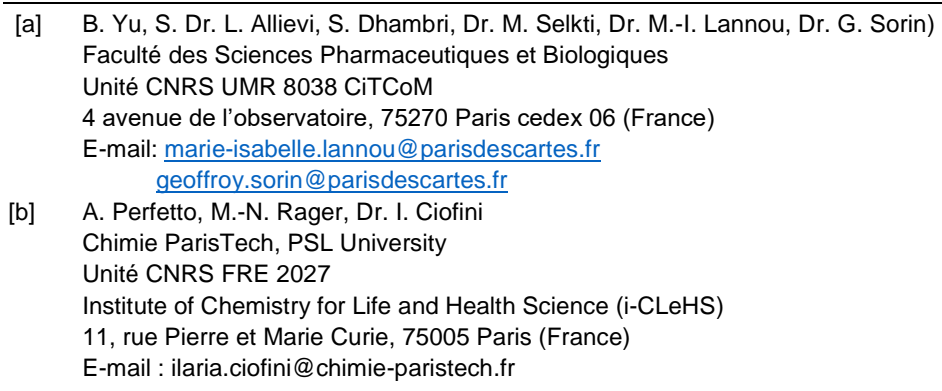

\begin{abstract}
A formal [3+2] cyclization mediated by silver(I) oxide and DBU is described herein. Through a broad variety of carbonyl compounds, this system can promote cyclization reactions with high yield (up to $85 \%$ ) and diastereoselectivity (up to 95:5) for a straightforward access to complex and congested dihydrofuran derivatives in one step using smooth conditions. Based on DFT studies, the proposed mechanism would involve an allenyl silver intermediate.
\end{abstract}

\section{Introduction}

2,3-Dihydrofuran sub-units can be encountered in a wide range of natural and synthetic products exhibiting, in some cases, biologically interesting profiles. ${ }^{[1]}$ Additionally, such scaffolds can also be regarded as attractive precursors in an array of organic transformations. ${ }^{[2]}$ Based on these considerations, considerable efforts have been devoted to the development of efficient accesses to 2,3-dihydrofuran units by various approaches. ${ }^{[3,4,5]}$ Among them, intra- or intermolecular [3+2] cycloadditions constitute a powerful tool to reach such heterocycles ${ }^{[6]}$ and more generally, heterocyclic 5-membered rings. In this field, the vast majority of transformations encountered implies hetero 1,3-dipolar reagents or their synthetic equivalent for reaching a broad variety of heterocyclic molecules. ${ }^{[7]}$ However, access to cyclic frameworks by means of cycloadditions reveals to be much more challenging in cases where all-carbon 1,3-dipoles are involved due to the difficulty to generate such species. ${ }^{[8]}$ To overcome this issue, the activation of double or triple bonds by means of transition metals appears to be an attractive method. However, very specific substrates are required, which constitutes a main drawback and narrows the application field. ${ }^{[8]}$ One area of improvement could consist in taking advantage of the strong alkynophilicity of "coinage metals", to carry out such kind of cyclizations.
Indeed, in 2007 Zhang's group reported an elegant [3+2] cycloaddition for the diastereoselective synthesis of cyclopentanone enol ethers using enones and allenyl MOM ethers mediated by gold catalysis. ${ }^{[9]}$ One year later, the same group published the synthesis of different 2,5-dihydrofuran motifs through Au-containing all-carbon 1,3-dipoles from propargylic ketals, showing the ability of gold to promote such cyclizations. ${ }^{[10]}$ In the course of their work on dual organocatalysis combining gold and aminocatalysis, Kirsch et al. unexpectedly obtained a tricyclic cis-fused dihydrofuran adduct by using a co-catalytic amount of $\left(\mathrm{Ph}_{3} \mathrm{P}\right)$ AuOTf (10 mol\%) and $\left(c-\mathrm{C}_{6} \mathrm{H}_{11}\right)(i-\mathrm{Pr}) \mathrm{NH}(20 \mathrm{~mol} \%)$ in xylenes at $150^{\circ} \mathrm{C}$ for $1 \mathrm{~h}$ (Figure 1). ${ }^{[11]}$ Surprisingly, this transformation has only been underlined in a single case by the authors and, to the best of our knowledge, has not been reported again in literature. Interestingly, in 2010, Zhang et al. demonstrated that the combination of $\mathrm{Ag}_{2} \mathrm{O}$ and $\mathrm{KOH}$ was able to promote formal intramolecular $[3+2]$ cycloaddition reactions, generating all-carbon 1,3-dipoles, under conventional heating ${ }^{[12]}$ or microwaves conditions. ${ }^{[13]}$ However, the scope of this transformation remains restricted to $N$ propargylamides bearing an electron withdrawing group on the nitrogen atom (Figure 1).

In the work developed herein, we expect to reach bi- or tricyclic complex structures containing 2,3-dihydrofuran cores in a single step from readily accessible compounds bearing an inactivated alkyne moiety. This reaction will proceed via a formal $\mathrm{Ag}(\mathrm{I})$ mediated [3+2] cyclization involving all-carbon 1,3-dipoles. This approach appears to be particularly challenging, since we envisioned to attain allenyl silver species through an unprecedented alkyne isomerization mediated by $\mathrm{Ag}(\mathrm{I})$ (Figure 1). As far as we know, the formation of an allenyl silver has only been reported by the Vermeer group through a 1,4-conjugated addition of an alkyl silver onto an ene-yne system (path a) or by transmetallation of an allenyl lithium species (path b). ${ }^{[14]}$ Moreover, the reactivity of such species has been little 
studied and the intramolecular cyclization targeted herein is unprecedented in literature (Figure 1).

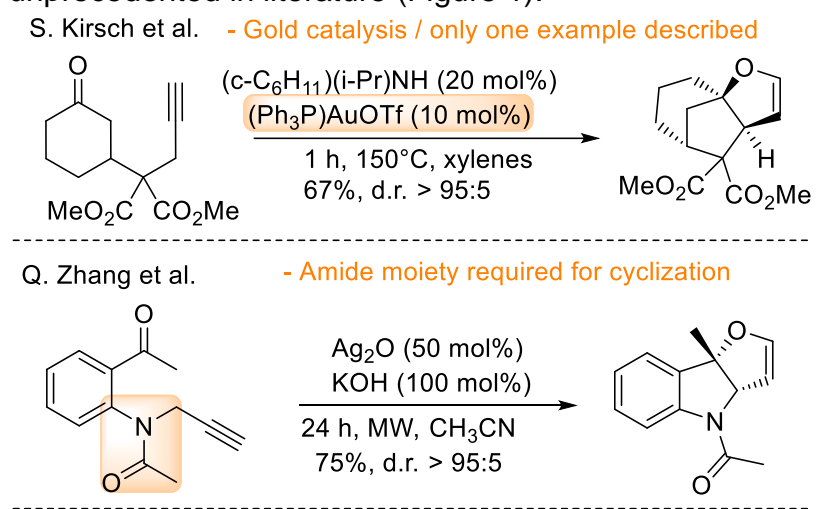

P. Vermeer et al. - Allenyl silver formations reported to date
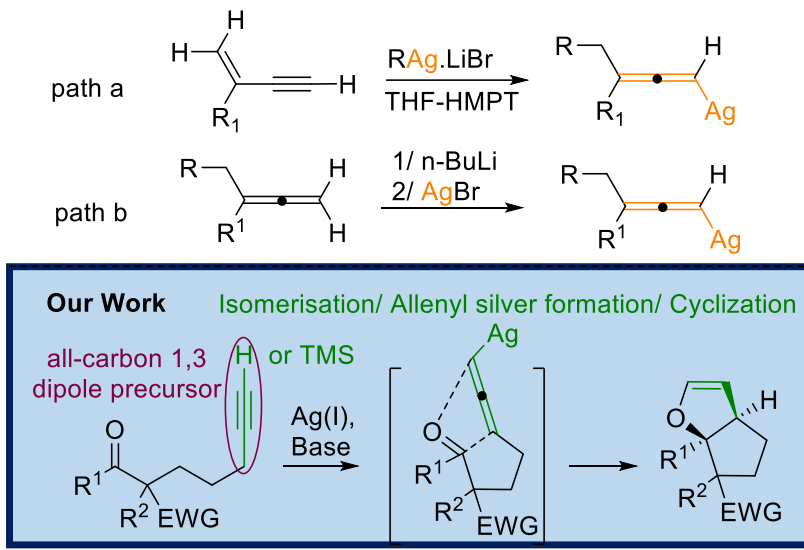

Figure 1 Silver/Base mediated alkyne isomerization/[3+2] cyclization reaction

\section{Results and discussion}

Silver was chosen as metal catalyst in this transformation since it is both significantly less expensive and more abundant than gold and less prone to undergo side-reactions than copper (i.e. Glaser-Hay coupling). Indeed, due to its [Kr] $4 d^{10} 5 s^{1}$ configuration, silver possesses a strong alkynophilicity and its ability to $\pi$-coordinate to unsaturated systems having low-lying empty orbitals makes it extremely interesting especially in the field of alkyne-based chemistry. ${ }^{[15]}$ In a preliminary survey, we chose the combination of $\mathrm{Ag}_{2} \mathrm{O} / \mathrm{DBU}$ in acetonitrile and 1,3-keto ester 1a as the substrate (Scheme 1).

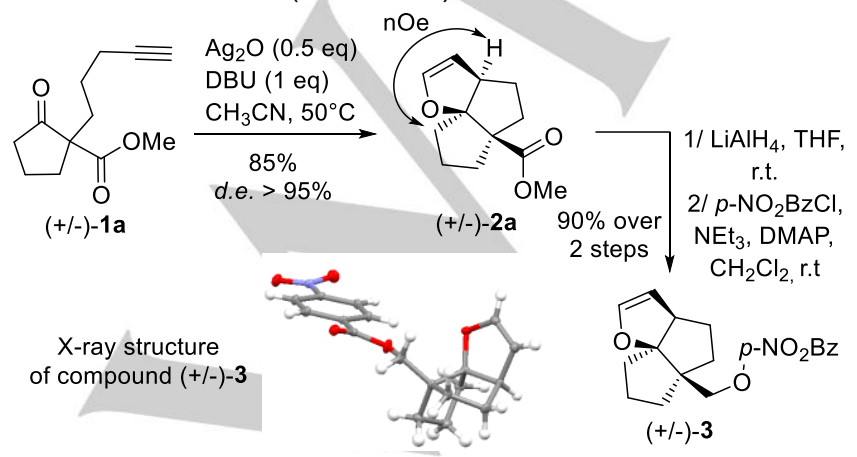

Scheme 1 Adduct 2a: Structure and stereochemistry determination
We were pleased to find a complete and clean conversion of $1 \mathrm{a}$ into the tricylic compound $2 \mathrm{a}$ at $50^{\circ} \mathrm{C}$ after $2 \mathrm{~h}$. The cyclized product was obtained in $85 \%$ yield with a total diastereoselectivity in favour of the cis-adduct without detection of the homo-coupling product. ${ }^{[16]}$ The stereochemistry was determined by NOE experiments and further confirmed by a single-cristal $X$-ray diffraction analysis of $p$-nitrobenzoyl derivative $3,{ }^{[17]}$ obtained after reduction of ester $\mathbf{2 a}$ and subsequent esterification of the resulting alcohol with $p$-nitrobenzoyl chloride ( $90 \%$ yield over two steps, Scheme 1).

Encouraged by this preliminary result, we focused on the optimization the reaction conditions (Table 1). A short screening of silver salts highlighted the ability of inexpensive silver(I) oxide to cleanly promote the cyclization after $2 \mathrm{~h}$ with a satisfying yield (85\%, Entry 1$)$. Silver nitrate and silver antimonate afforded $\mathbf{2 a}$ albeit in moderate yields, respectively $64 \%$ and $63 \%$ (Entry 2 and 4 ) whereas silver sulfate furnished only $32 \%$ of the desired product (Entry 3 ).

Table 1: Reaction optimization. Full data optimization is available in the ESI.

\begin{tabular}{|c|c|c|c|c|}
\hline & $(+/-)-1 \mathbf{a}^{\mathrm{O}}$ & $\begin{array}{c}\begin{array}{c}\text { Ag salt, Base } \\
\text { Solvent }\end{array} \\
\underset{50^{\circ} \mathrm{C}}{\longrightarrow}\end{array}$ & $(+/-)-\mathbf{2 a}$ & OMe \\
\hline Entry & Metal (eq.) & Base $^{a}$ & Solvent & Time, Yield $\%$ \\
\hline 1 & $\mathrm{Ag}_{2} \mathrm{O}(0.5)$ & DBU & $\mathrm{MeCN}$ & $2 h, 85 \%$ \\
\hline 2 & $\mathrm{AgNO}_{3}(1.0)$ & DBU & $\mathrm{MeCN}$ & $2 h, 64 \%$ \\
\hline 3 & $\mathrm{Ag}_{2} \mathrm{SO}_{4}(0.5)$ & DBU & $\mathrm{MeCN}$ & $3 h, 32 \%$ \\
\hline 4 & $\mathrm{AgSbF}_{6}(1.0)$ & DBU & $\mathrm{MeCN}$ & $30 \mathrm{~h}, 63 \%$ \\
\hline 5 & $\mathrm{Ag}_{2} \mathrm{O}(0.5)$ & $\mathrm{K}_{2} \mathrm{CO}_{3}$ & $\mathrm{MeCN}$ & $12 \mathrm{~h}, 80 \%$ \\
\hline 6 & $\mathrm{Ag}_{2} \mathrm{O}(0.5)$ & Pyrrolidine & $\mathrm{MeCN}$ & $20 \mathrm{~h}, 80 \%$ \\
\hline 7 & $\mathrm{Ag}_{2} \mathrm{O}(0.5)$ & $\mathrm{NEt}_{3}$ & $\mathrm{MeCN}$ & $20 \mathrm{~h},-^{\mathrm{c}}$ \\
\hline 8 & $\mathrm{Ag}_{2} \mathrm{O}(0.5)$ & DBU & DMF & $2 \mathrm{~h}, 76 \%$ \\
\hline 9 & $\mathrm{Ag}_{2} \mathrm{O}(0.5)$ & DBU & Toluene & $2 h, 85 \%$ \\
\hline 10 & $\mathrm{Ag}_{2} \mathrm{O}(0.5)$ & DBU & THF & $2 h, 84 \%$ \\
\hline 11 & $\mathrm{Ag}_{2} \mathrm{O}(0.5)$ & - & $\mathrm{MeCN}$ & $24 h, n . r$ \\
\hline 12 & - & DBU & $\mathrm{MeCN}$ & $24 h, n . r$ \\
\hline 13 & $\mathrm{Ag}_{2} \mathrm{O}(0.25)$ & DBU & $\mathrm{MeCN}$ & $48 \mathrm{~h}, 78 \%^{\mathrm{d}}$ \\
\hline 14 & $\mathrm{Ag}_{2} \mathrm{O}(0.25)$ & DBU & $\mathrm{MeCN}$ & $24 \mathrm{~h}, 83 \%{ }^{\mathrm{e}}$ \\
\hline 15 & $\mathrm{Ag}_{2} \mathrm{O}(0.5)$ & DBU & $\mathrm{MeCN}$ & $24 h, n \cdot r^{f}$ \\
\hline 16 & $\mathrm{P}(\mathrm{Ph})_{3} \mathrm{AuOTf}(0.1)$ & pyrrolidine & toluene & $2 h, n . r^{g}$ \\
\hline
\end{tabular}

a Each attempt was conducted with 1 eq. of base. ${ }^{b}$ Isolated Yield. ${ }^{c}$ Only traces of expected product were detected by ${ }^{1} \mathrm{H}$ NMR after $20 \mathrm{~h} .{ }^{\mathrm{d}}$ Reaction carried out under ambient atmosphere. ${ }^{e}$ Reaction carried out with $\mathrm{O}_{2}$ balloon. ${ }^{f}$ Reaction performed at r.t instead of $50^{\circ} \mathrm{C}$. ${ }^{9}$ Reaction performed at $110^{\circ} \mathrm{C}$

The reaction proceeded smoothly with $\mathrm{K}_{2} \mathrm{CO}_{3}$ as a base $(80 \%$, Entry 5$)$ and pyrrolidine $(80 \%$, Entry 6$)$ but only traces of the cyclized product were detected after $20 \mathrm{~h}$ by using $\mathrm{NEt}_{3}$ (Entry 7). Interestingly, the reaction is able to proceed in a wide range of solvents, providing $2 \mathbf{a}$ in satisfying yields (Entry 8-10, see SI). Finally, without DBU (Entry 11) or silver(I) oxide (Entry 12) no reaction was observed, establishing that the combination of silver reagent and base is mandatory to promote such cyclization (Entry 11 and 12). Using 0.25 eq. of $\mathrm{Ag}_{2} \mathrm{O}$ under air atmosphere afforded 2a (78\%, Entry 13) after a prolonged reaction time (48 h) which can be dramatically reduced to $24 \mathrm{~h}$ by conducting the reaction under $\mathrm{O}_{2}$ atmosphere (83\%, Entry 14). Interestingly, 
reactions can also be run with a catalytic amount of DBU $(0.1$ eq) without significant lengthening of the reaction time $(3 \mathrm{~h}$ instead of $2 \mathrm{~h}$ ). However, for accuracy and reproducibility considerations, we chose to perform the reactions with 1 equivalent of DBU instead of 0.1 . Optimized conditions do not provide the product when the reaction is conducted at $r . t$ (Entry 15). Also, we performed the reaction under conditions close to those reported by Kirsch but no product was detected (Entry 16)

Next, the scope of the reaction was examined: Our optimized conditions $\left(\mathrm{Ag}_{2} \mathrm{O}\right.$ : 0.5 eq., DBU: 1 eq. in $\mathrm{MeCN},[\mathrm{C}]$ $=0.24 \mathrm{M})$ were first applied to various cyclic ketones (Scheme 2).

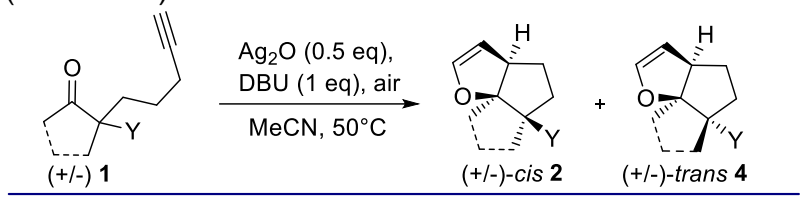<smiles>C#CCCC1(C(=O)OCC)CCCCC1=O</smiles>

$(+/-)-1 b$

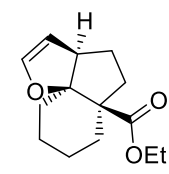

$(+/-)-\mathbf{2 b}, 85 \%$ cis/trans $>95: 5$

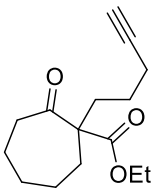

$(+/-)-1 c$

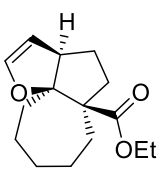

$(+/-)-2 c / 4 c, 58 \%$ cis/trans 55:45<smiles>C#CCCCC1(C(=O)OC)CCc2ccccc2C1=O</smiles>

$(+/-)-1 d^{\text {OEt }}$<smiles>CCOC(=O)[C@]12CCc3ccccc3[C@]13OC=C[C@H]3CC2</smiles>

$(+/-)-2 d$, traces

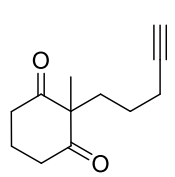

$(+/-)-1 e$

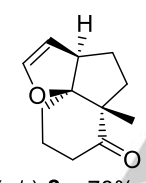

$(+/-)-2 e, 78 \%$ cis/trans $>95: 5$<smiles>C#CCCC1(C(=O)OC)CN(C(=O)OCc2ccccc2)CCC1=O</smiles>

$(+/-)-1 f$

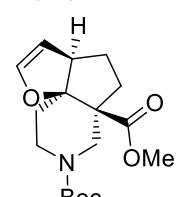

(+l-)-2f, $80 \%$

$(+/-)-2 f, 80 \%$,
cis/trans $>95: 5$

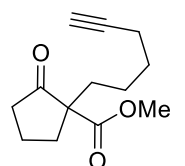

$(+/-)-1 g$

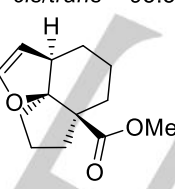

$(+/-)-2 \mathrm{~g}, 65 \%$ cis/trans $>95.5$

Scheme 2 Cyclization reactions of cyclic ketones ${ }^{*} 2 g$ was obtained under Condition B (see Scheme 3)
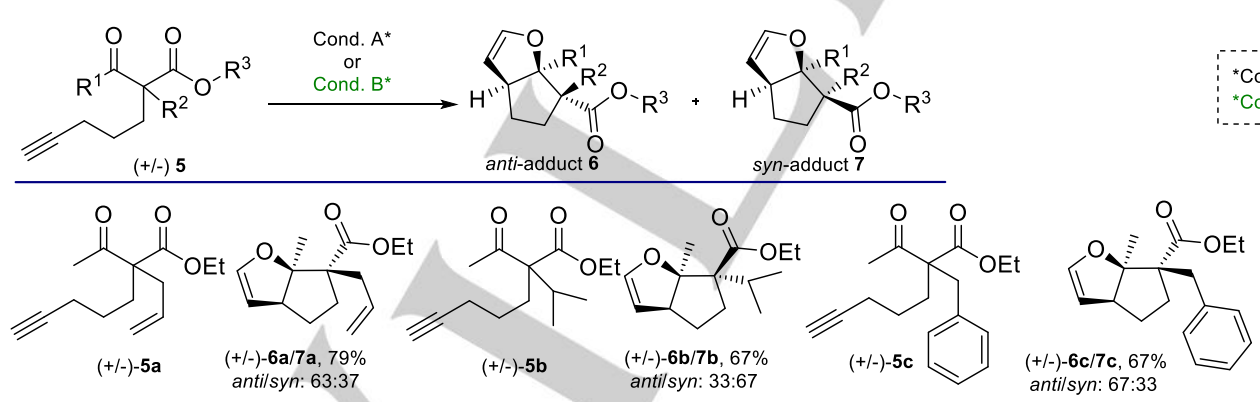

*Conditions $\mathrm{A}: \mathrm{Ag}_{2} \mathrm{O}(0.5 \mathrm{eq}), \mathrm{DBU}, \mathrm{CH}_{3} \mathrm{CN}, 50^{\circ} \mathrm{C}$, air *Conditions $\mathrm{B}: \mathrm{Ag}_{2} \mathrm{O}(0.5 \mathrm{eq}), \mathrm{DBU}$, Toluene, $75^{\circ} \mathrm{C}, \mathrm{O}_{2}$

substrates (1b) occured under mild conditions and 4 yields were obtained (up to $85 \%$ ) with a total diastereoselectivity in favour of the cis-adduct. We assumed that the selectivity is imposed by the configuration at the spiro carbon. Hence, for geometry and distance considerations, the ketone can be only attacked in a syn-periplanar fashion leading to the (+/-)-cis-isomer. Surprisingly, sevenmembered ring analog 1c was reluctant to cyclize and two equivalents of silver were necessary to attain a good conversion. Additionally, the cyclized products $2 \mathrm{c} / \mathbf{4 c}$ were obtained as a mixture of two diastereoisomers $\left(55: 45\right.$ by ${ }^{1} \mathrm{H}$ NMR) probably due to a higher conformational flexibility. Starting from the naphtalenone derivative 1d, no cyclization occured even under heating in a sealed tube at $100^{\circ} \mathrm{C} \cdot{ }^{[18]}$ Tricyclic ketone $2 \mathrm{e}$ was obtained in $78 \%$ yield from the corresponding symmetrical diketone 1e. Noteworthy, these cyclization conditions were also suitable to heterocyclic compounds and piperidine derivative $2 \mathbf{f}$ could be isolated in satisfying yield ( $80 \%)$. To our delight, using conditions B (see Scheme 3) allowed the extension to substrate with longer chain $(\mathbf{1 g})$ in order to reach six-membered-ring analog with good yield and high selectivity for the cis-isomer $\mathbf{2 g}$. The reactivity of linear ketones was next surveyed by varying the substitution of the malonate, the nature of the ketone and/or the influence of the functional group in beta position. We first studied the behaviour of different linear compounds towards the optimized cyclization conditions by tuning the nature of the substituent in alpha position to the ketone $\left(R^{2}\right)$. Substitution by an allylic chain (compound $\mathbf{5 a}$ ) as well as neutral- (5c) or enriched- (5d) benzylic chains was not deleterious to the reaction and good reactivities were observed along with modest selectivities in favour of the antiadduct (63:37, 67:33 and 63:37, respectively). Astonishingly, the diastereo-
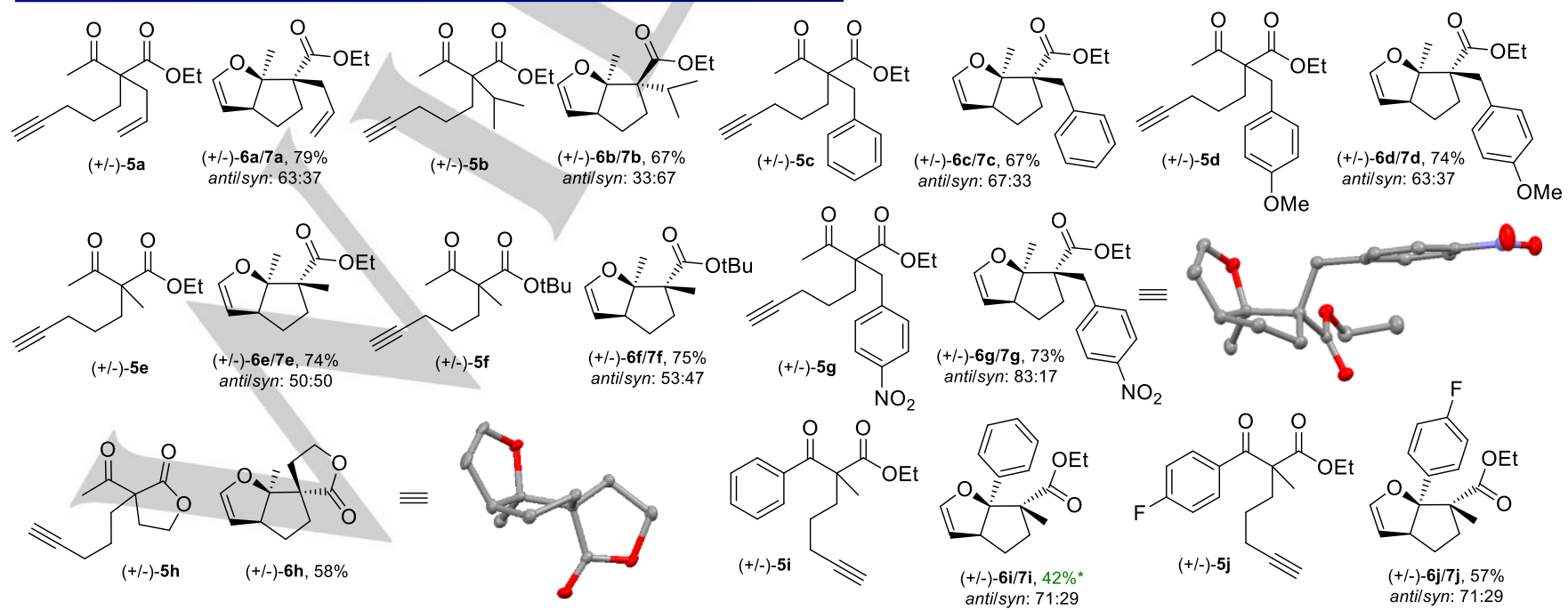
-meric ratio raised to $83: 17$ when the aromatic moiety was substituted by a $p$-nitro group $(\mathbf{5 g}) \cdot{ }^{[17]} \mathrm{A}$ bulkier isopropyl chain $\mathbf{5 b}$ delivered the corresponding bicyclic compound in $67 \%$ yield with inversion of the diastereomeric ratio in favour of the syn-adduct (7b), evidencing that the steric hindrance at this position is not detrimental to the reaction but strongly influences the selectivity. Modification of the size of the ester provided the expected 2,3dihydrofurans in good yields, however without notable improvement of the diastereoselectivity. On the contrary, the anti isomer $6 \mathrm{~h}$ was exclusively obtained with $58 \%$ yield when the lactone $5 \mathbf{h}$ was used. ${ }^{[17]}$ Unlike benzylic ketone $\mathbf{5 j}$, ketone $\mathbf{5 i}$ was reluctant to cyclize under conditions $A$ while applying conditions $B$ afforded good conversion, providing bicyclic compounds $6 \mathbf{i} / 7 \mathbf{i}$ and $6 \mathbf{j} / 7 \mathbf{j}$ (in 42 and $57 \%$ yield, respectively) with a similar selectivity towards the anti-isomer, along with degradation products. Finally, the substitution pattern of the triple bond was examined. To this aim, the reaction was conducted onto different substituted alkynes bearing either methyl (1h), phenyl (1i) or TMS (1j) groups (Scheme 4)

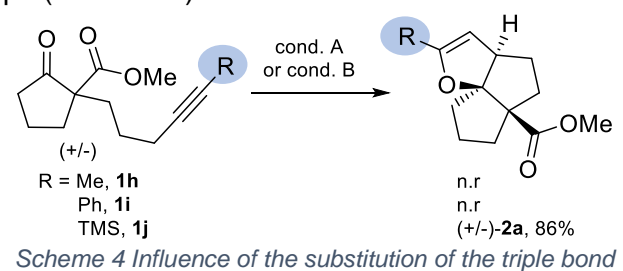

Reactions onto $\mathbf{1 h}$ or $\mathbf{1 i}$ were ineffective under both conditions ( $A$ or B). On the contrary, when trimethylsilylalkyne $\mathbf{1 j}$ was submitted to conditions $A$, it was smoothly converted into the cyclized product $2 \mathbf{a}(R=H)$. This result suggests a preliminary insertion of silver into the C-Si bond, which is consistent with the well-known propensity of terminal alkynes and TMS alkynes to undergo a metalation step under similar conditions. ${ }^{[19,20]}$

In order to provide insights into the mechanism and to provide a rationale for the diastereoselectivity, we studied the first five steps of the $\mathrm{Ag}(\mathrm{I})$ mediated cycloaddition reaction mechanism by means of Density Functional Theory (DFT) approaches. ${ }^{[21]}$ The computed reaction path together is presented in Figure 2, while computational details together with the labelling scheme are reported in Supporting Information. Two most probable isomers of $\mathbf{B H}^{+}$and the two most probable approaches of $\mathbf{B}$ to $\mathrm{Ag}$ have been computed (see supporting information for the related structures). We would like to underline that other trials starting from other B to Ag geometry always lead to one of the two species here reported. The data discussed here correspond to the arrangements of the $\mathbf{B} / \mathrm{BH}^{+}$and reactants providing the lowest energies.

A multistep pathway is proposed to explain the reaction mechanism up to the first cyclization process involving the carbonyl group and carbons of alkynyl residue (Figure 1). The analyzed reaction mechanism proceeds through five steps. Starting from the very stable silver alkynyl intermediate (I), the initial step corresponds to the proton transfer from conjugated acid of $\mathrm{DBU}\left(\mathrm{BH}^{+}\right.$in Figure 2) to I leading to the formation of intermediate II. This step proceeds with a barrier of $14.40 \mathrm{kcal} / \mathrm{mol}$ (Table 1 in Supporting Information) and leads to the formation of stable intermediate II. A subsequent proton transfer from II to DBU
(B in Figure 2) generates the silver allenyl intermediate (III). The energetic barrier to overcome for its formation is found to be 12.07 $\mathrm{kcal} / \mathrm{mol}$ (Figure 2). Of note the back reaction from II to $\mathbf{I}$ is characterized by a very small barrier so that we can assume that $\mathbf{I}$ is easily reformed. Following the energetic span model, ${ }^{[22]}$ we can therefore assume that the energy span is related to the difference between the energy of $\mathbf{I}$ and TS2, leading to an effective barrier of $22.45 \mathrm{kcal} / \mathrm{mol}$ determining the reaction turnover. The III allenyl intermediate is characterized by practically equivalent $\mathrm{C}_{1}-\mathrm{C}_{2}$ and $\mathrm{C}_{2}-\mathrm{C}_{3}$ bonds (1.30 $\AA$ ). From this intermediate, a first cyclization occurs via the TS3 transition state: the $\mathrm{C}_{3}-\mathrm{C}_{4}$ bond decrease achieving a value

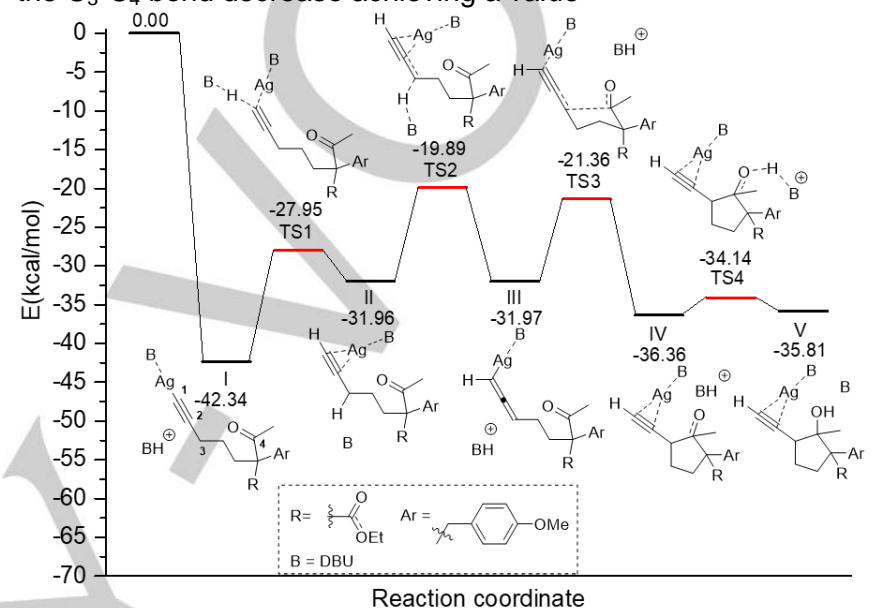

Figure 2 Computed reaction mechanism ( $\Delta E$ in $\mathrm{kcal} / \mathrm{mol}$ of all stationary points are reported with respect to the sum of all isolated species participating to the reaction).

of $2.20 \AA$ and suggesting the closure of the cycle. TS3 lies at $10.61 \mathrm{kcal} / \mathrm{mol}$ higher in energy with respect to the III and leads to the formation of intermediate IV, characterized by a $\mathrm{C}_{3}-\mathrm{C}_{4}$ bond of $1.57 \AA$ and thus by a fully formed 5-carbon cycle. Of note in IV the silver atom approaches the oxygen (Ag-O bond of $2.15 \AA$ ), while $\mathrm{C}_{1}-\mathrm{Ag}$ and $\mathrm{C}_{2}-\mathrm{Ag}$ are elongating up to $2.70 \AA$. Comparing the atomic (Mulliken) charges computed for the TS3 and the IV, it is found that $\mathrm{C}_{4}$ becomes more electrophilic (from -1.91|e-| to $0.22|\mathrm{e}-|)$, while the oxygen becomes more nucleophilic (from $0.34|e-|$ and $-0.49|e-|)$. This makes possible to envisage a proton transfer from the conjugated acid $\mathrm{BH}^{+}$of $\mathrm{DBU}$ to the oxygen atom of IV. The very low energy barrier $(2.23 \mathrm{kcal} / \mathrm{mol})$ computed for this reaction confirmed this hypothesis.

In the corresponding transition state (TS4), the $\mathrm{Ag}$ atom is found to bridge the oxygen and the alkynyl lateral group $\left(\mathrm{C}_{1}-\mathrm{Ag}, \mathrm{C}_{2}-\mathrm{Ag}\right.$, $\mathrm{Ag}-\mathrm{O}$ bonds in the 2.30-2.40 $\AA$ range), while the $\mathrm{C}_{4}-\mathrm{O}$ bond is elongated up to $1.41 \AA$ and the $\mathrm{O}-\mathrm{H}$ bond is forming $(1.21 \AA$ ). Indeed, the $\mathbf{V}$ intermediate shows a proton bonded to the oxygen (O-H bond $1.02 \AA$ ) and the silver atom coordinated to the carbons of alkynyl residue $\left(\mathrm{C}_{1}-\mathrm{Ag}, \mathrm{C}_{2}-\mathrm{Ag}\right.$ around 2.30-2.35 $\AA$ ).

At this stage, the reaction proceeds via a second cyclization process involving the alkynyl lateral group and the oxygen to form the dihydrofuran cycle ${ }^{[23]}$ which actually we computed to be extremely thermodynamically favored $(\Delta \mathrm{E}=-119.16 \mathrm{Kcal} / \mathrm{mol}$, see SI).

In order to disclose the origin of the diastereoselectivity, we computed the first three steps of the reaction mechanism following two approaches leading to anti or syn diasteroisomers 
(Figure 3; all computational details are reported in the Supporting Information). All computed energy barriers are similar for both diasteroisomers paths nonetheless we observe that Ila is effectively more stable than Ilb of $4.19 \mathrm{kcal} / \mathrm{mol}$. Indeed, the destabilizing interaction between the oxygen lone pairs of both carbonyls (O-O bond $2.80 \AA$ ) disfavors the syn adduct. With the aim of further validating the hypothesis that regioselectivity may be related to the presence (or absence) steric interactions for one of the adducts, we extended the study of reaction step II to compound 5e. (see Figure 3 in the Supporting Information).

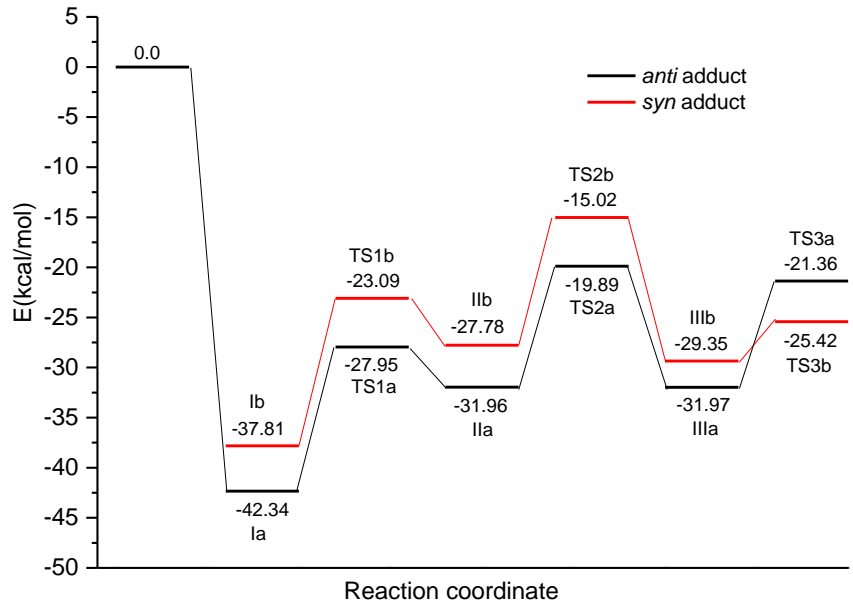

Figure 3 Computed $\Delta E$ of the first three steps of the reaction mechanism for the anti/syn adducts.

The reaction then proceeds with similar barriers both along the a and $b$ pathway, suggesting that the final product depends on the most favorable initial intermediate. Indeed, with the aim of further validating our hypothesis, we extended the study of the reaction steps of compound $\mathbf{5 d}$. In this case, comparing the two optimized diasteroisomers, it is worth to notice that while the energy difference between the anti/syn adducts for the first step is similar to the value observed for compound 5 e $(3.43 \mathrm{kcal} / \mathrm{mol})$, it decreases down to $1.39 \mathrm{kcal} / \mathrm{mol}$ at step II. Since such energy difference is very low, we can assume that this is the origin of the absence of diastereoselectivity. Indeed, for this compound, the destabilizing interaction is substantially decreased upon substitution with less sterically-hindered methyl group, since the oxygen lone pairs of both carbonyls are located further apart in this case (O-O bond $3.00 \AA$ see Figure 3 in the $\mathrm{SI}$ ).

Experimentally, we ran the reaction on bulkier amide $\mathbf{8}$ moiety leading to a drastic enhancement of the diastereomeric ratio (antilsyn: > 95:5) ( ).

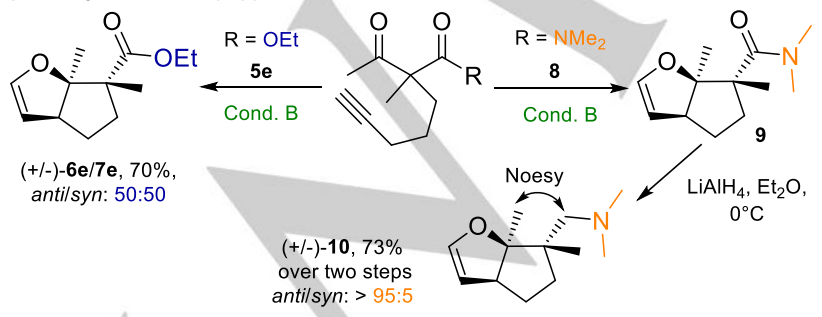

Scheme 5 Selectivity on $\beta$-keto amide versus $\beta$-keto ester

However, we were unable to confirm the stereochemistry at this stage. In order to determine the relative configuration of the cyclized product, the amide 9 was subsequently reduced into the corresponding amine $\mathbf{1 0}$ in $\mathbf{7 3} \%$ yield over two steps. A NOE

experiment unambiguously evidenced anti adduct $\mathbf{1 0}$ as the major compound. In parallel, performing the reaction on ethyl ester $5 \mathrm{e}$ under conditions B did not allow improvement of the diastereomeric ratio $(50: 50)$, underlining the primary importance of the nature of the electron withdrawing group on the diastereoselectivity. Noteworthy, conditions B allowed a better conversion without influencing the diastereoselectivity.

\section{Conclusion}

This unprecedented formal silver mediated [3+2] cyclization appears as a valuable tool for the synthesis of complex and/or congested polycyclic dihydrofurans. As an example, the approach developed herein would permit a straightforward access to precursor natural compounds, which possess an angularly fused tricyclic lactone backbone like alliacol or teucrolivin, under smooth conditions (Figure 4)

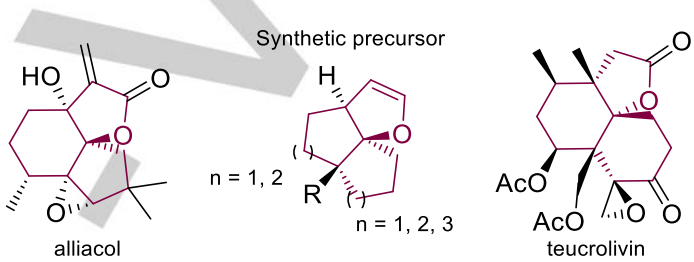

Figure 4 Dihydrofuran core as useful synthetic intermediate in natural products synthesis

In summary, we have developed a new formal [3+2] cyclization promoted by silver(I) oxide and DBU from readily available starting B-dicarbonyl compounds. The reaction is broad in scope, proceeds in mild conditions and allows an access to complex and congested molecules in a single step. This transformation is highly tolerant towards a wide range of solvents and bases (in stoichiometric or in catalytic amounts), thus facilitating its adaptation to structurally diverse, and potentially sensitive substrates. DFT calculations have demonstrated the formation of an allenyl silver intermediate by isomerization of the corresponding alkyne. Although the description of this species remains particularly scarce in the literature, its formation is a prerequisite in the promotion of the reaction. Moreover, DFT calculations have also allowed to determine the thermodynamic origin of the syn/anti diastereoselectivity for $\beta$-dicarbonyl compounds bearing an ester group. More generally, through this methodology, we highlighted a new reactivity of silver salts towards terminal alkyne. Thanks to this unprecedented isomerization reaction, we opened the way to a new field of transformations. The peculiar reactivity of allenyl silver species is currently under investigation in our laboratory.

\section{Experimental Section}

See supporting informations.

\section{Acknowledgements}


B. Y. thanks the China Scholarship Council for Ph.D grant. I.C. and A.P thank the European Research Council (ERC) for funding under the European Union's Horizon 2020 research and innovation programme (grant agreement No 648558, STRIGES CoG grant). We would like to thank Pr. P. Belmont for fruitful discussions and single-cristal $\mathrm{X}$-ray diffraction service from ICMMO-UMR8182 Orsay.

Keywords: Allenyl silver $•$ dihydrofuran $\bullet$ isomerization • intramolecular cyclization

[1] T. G. Kilroy, T. P. O'Sullivan, P. J. Guiry, Eur. J. Org. Chem., 2005, 23, 4929-4949.

[2] B. H. Lipshutz, Chem. Rev., 1986, 86, 795-819. b) B. M. Fraga, Nat. Prod. Rep., 1992, 9, 217-241. c) A. T. Merritt, S. B. Ley, Clerodane, Nat. Prod. Rep., 1992, 9, 243-287. d) M. M. Faul, B. E. Huff, Chem. Rev., 2000, 100, 2407-2474. e) M. C. Elliott, J. Chem. Soc. Perkin Trans. 1, 2002, 2301-2323. f) F. Garzino, A. Méou, P. Brun, Synthesis, 2003, 0598-0602. g) T. G. Kilroy, T. P. O'Sullivan, P. J. Guiry, Eur. J. Org. Chem., 2005, 4929-4949. (h) R. A. Brawn, J. S. Panek, Org. Lett., 2010, 12, 4624-4627.

[3] For some reactions using chiral auxiliaries and precursors, see: a) $\mathrm{H}$. J. Gais, L. R. Reddy, G. S Babu, G. Raabe, J. Am. Chem. Soc., 2004 126, 4859-4864. b) W. Xia, C. Yang, B. O. Patrick, J. R. Scheffer, C. Scott, J. Am. Chem. Soc., 2005, 127, 2725-2730. c) R. K. Bowman, J. S. Johnson, Org. Lett., 2006, 8, 573-576. d) J.-C. Zheng, C.-Y. Zhu, X.L. Sun, Y. Tang, L.-X. Dai, J. Org. Chem., 2008, 73, 6909-6912.

[4] For some metal-mediated cyclization reactions, see: a) H. M. L. Davies, G. Ahmed, R. L. Calvo, M. R. Churchill, D. G. Churchill, J. Org. Chem., 1998, 63, 2641-2645. b) D. A. Evans, Z. K. Sweeney, T. Rovis, J. S. Tedrow, J. Am. Chem. Soc., 2001, 123, 12095-12096. c) S. Son, G. C. Fu, J. Am. Chem. Soc., 2007, 129, 1046-1047. d) J.-L. Zhou, L.-J. Wang, H. Xu, X.-L. Sun, Y. Tang, ACS. Catal., 2013, 3, 685-688. e) D. Sinha, A. Biswas, V. K. Singh, Org. Lett., 2015, 17, 3302-3305. f) Y. Zhou, F.-L. Zhu, Z.-T. Liu, X.-M. Zhou, X.-P. Hu, Org. Lett., 2016, 18, 2734-2737. g) J. Reece, P. Ritashree, A. P. Nicholas, C. E. Sear, P. W. Smith, A. Ribaucourt, D. M. Hodgson, Org. Biomol. Chem., 2016, 14, 5875-5893. h) O. El-Sepelgy, A. Brzozowska, J. Sklyaruk, Y. K. Jang, V. Zubar, M. Rueping, Org. Lett., 2018, 20, 696-699.

[5] For some organocatalytic reactions, see: a) R.-Q. Mei, X.-Y. Xu, L. Peng, F. Wang, F. Tian, L.-X. Wang, Org. Biomol. Chem., 2013, 11 1286-1289. b) N.-J. Zhong, F. Wei, Q.-Q. Xuan, L. Liu, D. Wang, Y.-J. Chen, Chem. Commun., 2013, 49, 11071-11073. c) M. A. Calter, A. Korotkov, Org. Lett., 2015, 17, 1385-1388. d) Y. Cheng, Y. Han, P. Li, Org. Lett., 2017, 19, 4774-4777.

[6] For some representatives [3+2] reactions, see : a) J. Tsuji, I. Watanabe, I. Minami, I. Shimizu, J. Am. Chem. Soc., 1985, 107, 2196-2198. b) I. Minami, M. Yuhara, I. Watanabe, J. Tsuji, J. Organomet. Chem., 1987, 334, 225-242. c) F.-L. Zhu, Y.-H. Wang, D.-Y. Zhang, J. Xu, X.-P. Hu, Angew. Chem. Int. Ed., 2014, 53, 10223-10227. d) Y. Zhou, F. -L. Zhu, Z.-T. Liu, X.-M. Zhou, X.-P. Hu, Org. Lett., 2016, 18, 2734-2737.

[7] For selected reviews, see: a) T. Hashimoto, K. Maruoka, Chem. Rev., 2018, 115, 5366-5412. b) L. M. Stanley, M.P. Sibi, Chem. Rev., 2008, 118, 2887-2902. c) H. Pélissier, Tetrahedron, 2007, 63, 3235-3285. d) V. Nair, T. D. Suja, Tetrahedron, 2007, 63, 12247-12275. e) K. Harju, J. Yli-Kauhaluoma, Mol. Divers., 2005, 9, 187-207. f) K. V. Gothelf K. A. Jørgensen, Chem. Rev., 1998, 98, 863-909. g) M. S. Singh, S. Chowdhury, S. Koley, Tetrahedron, 2016, 72, 1603-1644. h) C. Nájera, J. M. Sansano, J. Organomet. Chem., 2014, 771, 78-92.

[8] For selected reviews and books, see: a) D. M. T. Chan, in Comprehensive Organic Synthesis $1^{\text {st }}$ ed. (Eds.: B. M. Trost, I. Fleming), Pergamon, Oxford, New York, 1991, pp. 271-314. b) N. Iwasawa, in Comprehensive Organic Synthesis $2^{\text {nd }}$ ed. (Eds.: P. Knochel, G. A. Molander), Elsevier, Oxford, New York, 2014, pp. 273 350. c) S. Yamago, E. Nakamura, Org. React., 2002, 61, 1-217. d) P. Le Marquand, W. Tam, Angew. Chem. Int. Ed., 2008, 47, 2926-2928. e) M. E. Welker, Chem. Rev. 1992, 92, 97-112.
[9] X. Huang, L. Zhang, J. Am. Chem. Soc. 2007, 129, 6398-6399. For key reviews on homogeneous gold catalysis, see: a) D. Pflaesterer, A. S. K. Hashmi, Chem. Soc. Rev., 2016, 45, 1331-1367. b) A. S. K. Hashmi, Chem. Rev., 2007, 107, 3180-3211. c) A. S. K. Hashmi, G. J. Hutchings, Angew. Chem. Int. Ed., 2006, 45, 7896-7936.

[10] G. Zhang, L. Zhang, J. Am. Chem. Soc. 2008, 130, 12598-12599.

[11] J. T. Binder, B. Crone, T. T. Haug, H. Menz, S. F. Kirsch, Org. Lett., 2008, 10, 1025-1028. For a highlight on the combination of gold catalysis and organocatalysis, see: A. S. K. Hashmi, C. Hubbert, Angew. Chem. Int. Ed., 2010, 49, 1010-1012.

[12] Z. Zhang, Q. Zhang, Z. Ni, Q. Liu, Chem. Commun., 2010, 46, 12691271.

[13] Z. Zhang, S. Fang, Q. Liu, G. Zhang, Adv. Synth. Catal., 2012, 354, 927-932.

[14] H. Westmijze, H. Kleijn, H.J.T. Bos, P. Vermeer, J. Organomet. Chem., 1980, 199, 293-297. b) H. Westmijze, K. Ruitenberg, .I. Meijer, P. Vermeer, Tetrahedron. Lett., 1980, 21, 1771-1772. c) J. Meijer, K. Ruitenberg, H. Westmijze, P. Vermeer, Synthesis, 1981, 551-554.

[15] For recent results on silver-catalyzed conversions of alkynes, see: a) S. Dabral, U. Licht, P. Rudolf, G. Bollmann, A. S. K. Hashmi, T. Schaub, Green Chem., 2020, 22, 1553-1558. b) A. Ahrens, N. F. Heinrich, S. R. Kohl, M. Hokamp, M. Rudolph, F. Rominger, A. S. K. Hashmi, Adv. Synth. Catal., 2019, 361, 5605-5615. c) Y.-Y Yang, P. Antoni, M. Zimmer, K. Sekine, F.F. Mulks, L. Hu, L. Zhang, M. Rudolph, F. Rominger, A.S.K. Hashmi, Angew. Chem. Int. Ed., 2019, 58, 51295133. d) S. Dabral, B. Bayarmagnai, M. Hermsen, J. SchießI, V. Mormul, A. S. K. Hashmi, T. Schaub, Org. Lett., 2019, 21, 1422-1425. e) F. Chen, A. S. K. Hashmi, Org. Lett., 2016, 18, 2880-2882.

[16] For selected Ag catalysed Glaser-Hay coupling, see: a) Y.-Q. Zhang, N. Kepčija, M. Kleinschrodt, K. Diller, S. Fischer, A. C. Papageorgiou, F. Allegretti, J. Björk, S. Klyatskaya, F. Klappenberger, M. Ruben, J. V. Barth, Nat. Commun., 2012, 3, 1286-1293. b) H.-Y. Gao, H. Wagner, D.-Y. Zhong, J.-H. Franke, A. Studer, H. Fuchs, Angew. Chem., 2013 52, 4024-4028. c) H.-Y. Gao, H. Wagner, D.-Y. Zhong, J.-H. Franke, A. Studer, H. Fuchs, Angew. Chem. Int. Ed., 2013, 125, 4116-4120.

[17] Crystallographic data are available from the Cambridge Crystallographic Data Centre: a) Compound 3, reference CCDC no. 1972313. b) Compound $\mathbf{6 g}$, reference CCDC no. 1972314. c) Compound 6h, reference CCDC no. 1972315.

[18] Only traces of $\mathbf{2} \mathbf{d}$ along with degradation products were observed by ${ }^{1} \mathrm{H}$ NMR

[19] A. Vitérisi, A. Orsini, J-M. Weibel, P. Pale, Tett. Lett., 2006, 47, 27792781.

[20] U. Létinois-Halbes, P. Pale, S. Berger, J. Org. Chem., 2005, 70, 91859190.

[21] In all calculations, $\mathrm{Ag}^{+}$counterion was not taken into account.

[22] S. Kozuch, S. Shaik Acc. Chem. Res. 2011, 44, 101-110.

[23] For such cycloetherification mediated by silver see for example: B. Alcaide, P. Almendros, T. Martinez del Campo, R. Carrascosa, Eur. J. Org. Chem. 2010, 4912-4919. 


\section{Entry for the Table of Contents}

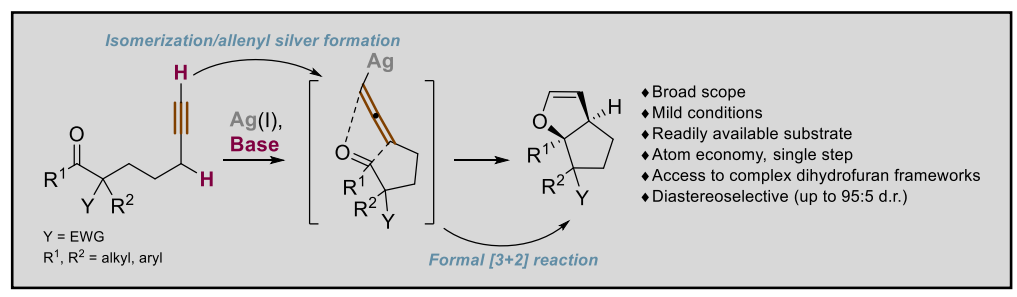

An unprecedented isomerization/allenyl silver formation/[3+2] cyclization promoted by a combination of silver salts and base are presented. The reaction allows the straightforward and diastereoselective (up to 95:5 d.r.) synthesis of complex dihydrofuran frameworks, under mild conditions from easily accessible substrates and is broad in scope. 